\title{
Letter to Editor; Prevention of Mother-to-Child HIV Transmission (PMTCT) Program in Iran: Challenges and Achievements
}

\author{
Ensiyeh Jenabi ${ }^{1}$ and Salman Khazaei ${ }^{2,{ }^{*}}$ \\ ${ }^{1}$ Autism spectrum Disorders Research Center, Hamadan University of Medical Sciences, Hamadan, Iran \\ ${ }^{2}$ Research Center for Health Sciences, Hamadan University of Medical Sciences, Hamadan, Iran \\ "Corresponding author: Research Center for Health Sciences, Hamadan University of Medical Sciences, Hamadan, Iran. Email: salman.khazaei61@gmail.com \\ Received 2018 August 26; Revised 2019 August 28; Accepted 2019 September 25.
}

Keywords: Infectious Disease Transmission, Mothers, Child, HIV

\section{Dear Editor,}

HIV/AIDS is the leading cause of death among women in the reproductive age worldwide. Furthermore, it is estimated that nearly 1000 children under the age of 15 years acquire HIV infection in the world each day; this is while over $90 \%$ of HIV infections among them are due to motherto-child transmission (1).

Prevention of mother-to-child transmission (PMTCT) programs provides antiretroviral treatment (ART) to HIVpositive pregnant women to stop their infants from acquiring the virus. Without treatment, the chance of HIV transmission from the mother to her child is $15 \%$ to $45 \%$, while through ART this risk reduces to below 5\% (2). Results of a systematic review on Sub-Saharan African countries showed that long-standing health-systems issues, such as staffing and accessibility to health services as well as community-level factors like stigma, fear of disclosure, and lack of partner support has the deterrent effect on using PMTCT programs (1). Below we introduce PMTCT program indicators in Iran and evaluate the effectiveness of this program for HIV among Iranian neonates born to HIV-positive mothers and describe the challenges and achievements of the program.

We used information of UNAIDS regarding elimination of mother-to-child transmission for Iran in 2018 (3). As shown in Figure 1, coverage of pregnant women who receive antiretroviral therapy (ARV) for PMCT in Iran was rising from 2010 to 2016 (13\% in 2010 vs. 60\% in 2016) and decreased afterward (55\% in 2017).

Number of new HIV positive child infections in Iran has an oscillating trend in recent years. Using PMTCT has led to a sharp decline in the number of new HIV child infections from 2014 onwards (Figure 2).
Iran has a great achievement in the field of early HIV diagnosis in infants. Figure 3 shows that this index in Iran reached from $2 \%$ in 2009 to $31 \%$ in 2017 . According this report HIV testing among pregnant women in Iran reached from $4 \%$ in 2015 to $24 \%$ in 2017.

The above results indicate that Iran has taken important steps in prevention of PMTCT. However, as PMTCT is not $100 \%$ effective, according to WHO the targets elimination of HIV is defined as reducing the final HIV transmission rate to $5 \%$ or less among breastfeeding women and to $2 \%$ or less among non-breastfeeding women by 2020 (4). Therefore, there is a long way to reaching the ideal state.

The World Health Organization (WHO) recommended a comprehensive approach to prevention of PMTCT, which should be considered in the PMTCT program and includes:

- Preventing new HIV infections among women in the reproductive age

- Preventing unintended pregnancies among HIV infected women

- Preventing HIV transmission from HIV infected mother to her child

- Providing appropriate treatment, care, and support to mothers living with HIV and their children and families (5).

From the year of 2006, the provision of ART for prevention of MTCT has been placed in the national guidelines regarding treatment and care of HIV positive patients. In 2013 a plan was conducted in 166 high-risk zones in 14 provinces in Iran with the aim of reducing MTCT. This plan contains prevention of infections in women and young girls; family planning and reproductive health for women infected with HIV, healthy childbirth for infected women, and newborn follow-ups, care, and treatment for infected newborns. Although requested HIV testing for all pregnant 


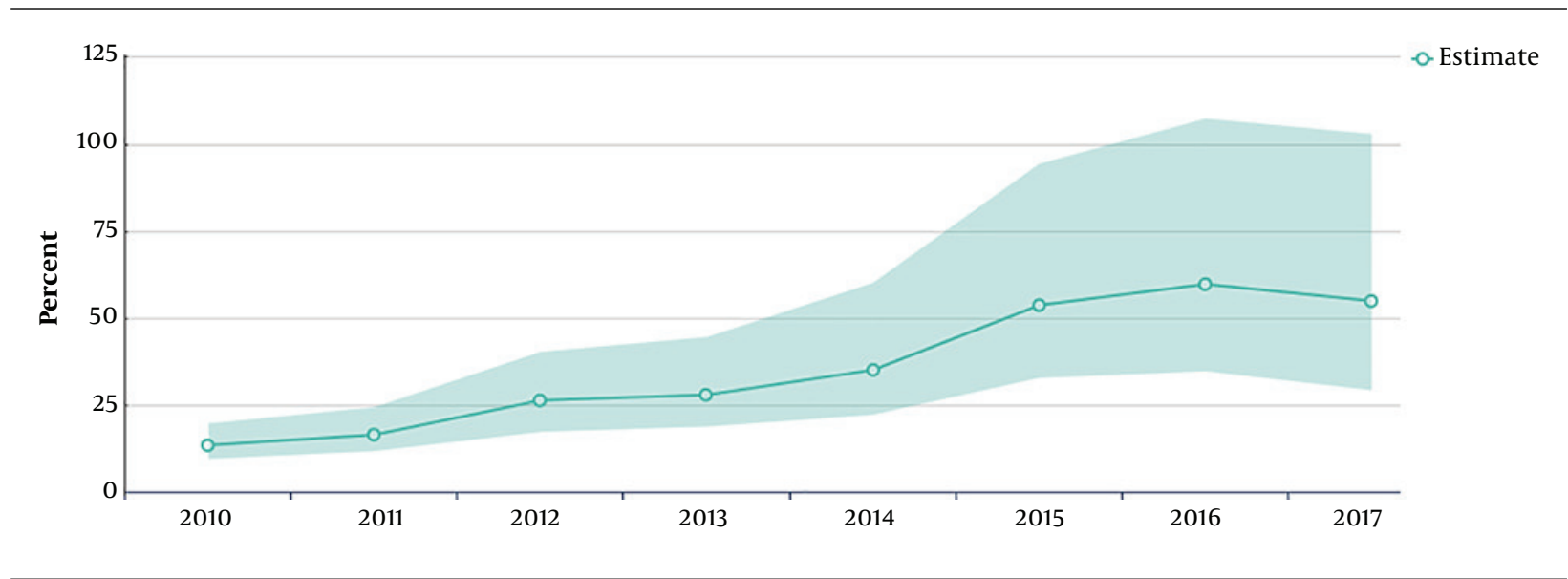

Figure 1. Coverage of pregnant women who receive ARV for PMCT in Iran (2010 - 2017)

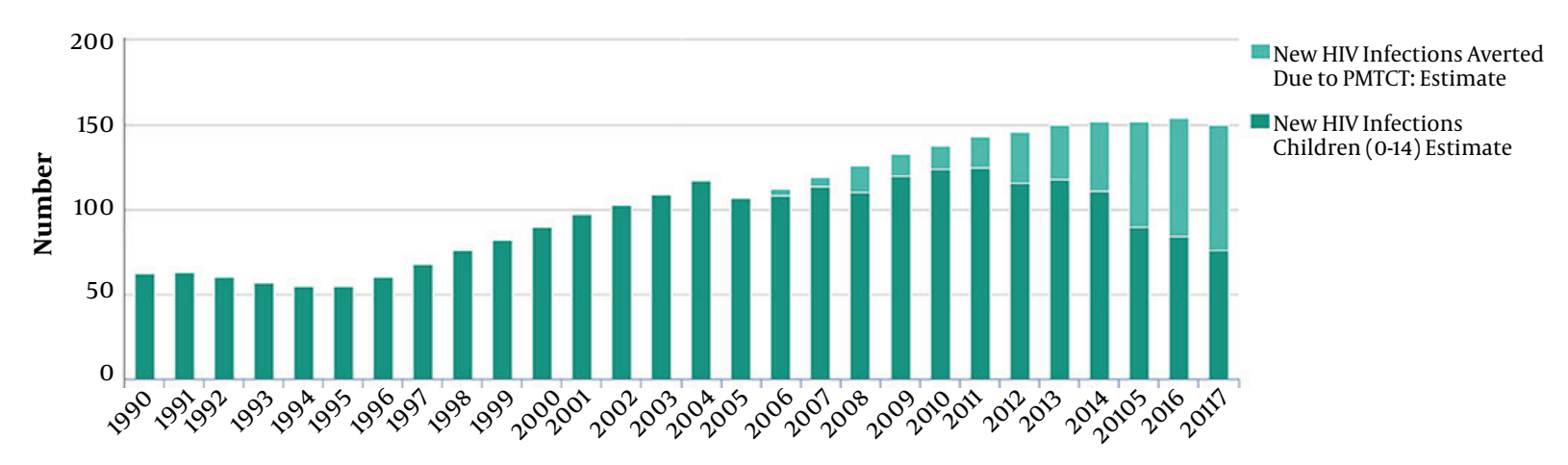

Figure 2. Number of new HIV child infections vs. number of new infections averted due to PMTCT in Iran

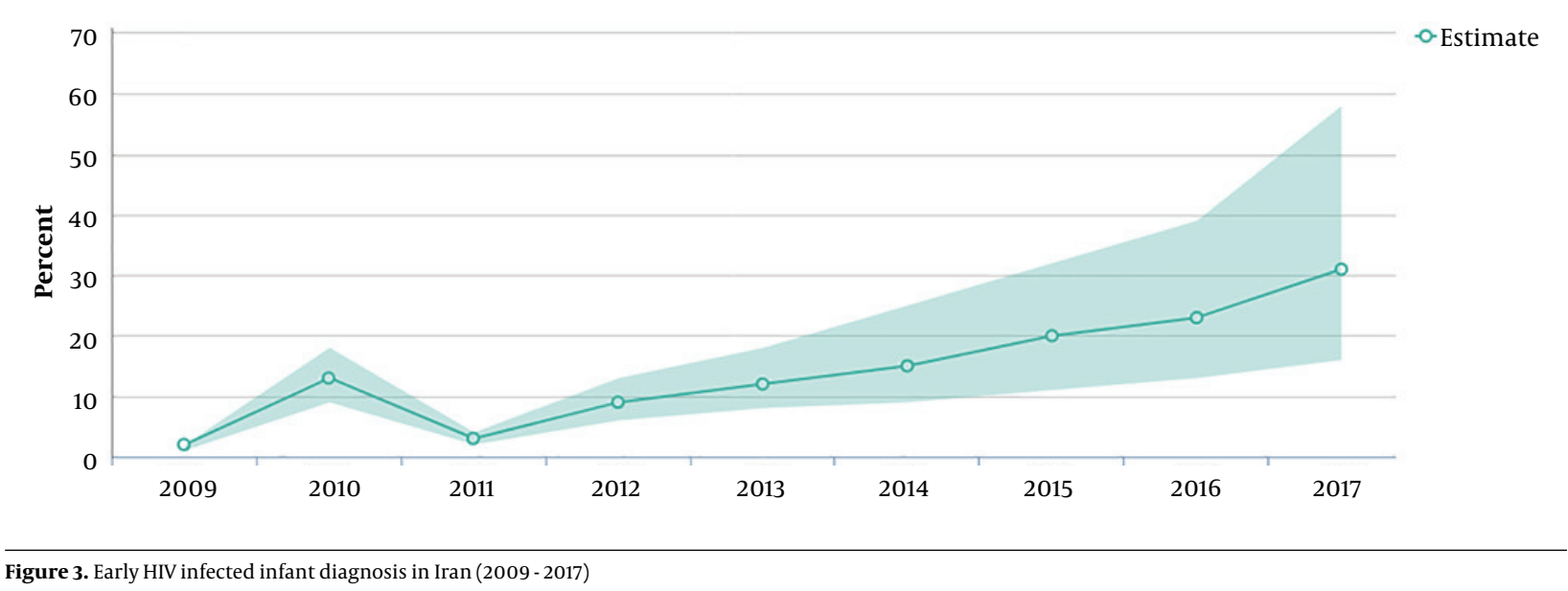

women are implemented routinely in many private and academic sector physicians, the real figure for HIV tests remains unknown in Iran (6).

Results of one study in Tehran showed that the knowl- edge of pregnant women about preventive methods and use of antiretroviral was very poor (7). Therefore, it seems that besides providing appropriate drugs and prevention facilities, providing prenatal educational programs on 
HIV/AIDS with emphasis on preventive measures and availability of antiretroviral medications is necessary for preventing PMTCT.

\section{Footnotes}

Conflict of Interests: This study had no conflict of interest.

\section{Funding/Support: This study had no financial support.}

\section{References}

1. Gourlay A, Birdthistle I, Mburu G, Iorpenda K, Wringe A. Barriers and facilitating factors to the uptake of antiretroviral drugs for prevention of mother-to-child transmission of HIV in subSaharan Africa: A systematic review. J Int AIDS Soc. 2013;16:18588. doi: 10.7448/IAS.16.1.18588. [PubMed: 23870277]. [PubMed Central: PMC3717402].

2. World Health Organization. Mother-to-child transmission of HIV. 2018. Available from: https://www.who.int/hiv/topics/mtct/about/en/.

3. UNAIDS. Elimination of mother-to -child transmission: Islamic Republic of Iran. 2018, [cited Aug 19, 2018]. Available from: http://aidsinfo.unaids. org.

4. UNAIDS. Start free stay free AIDS free. 2017.

5. World Health Organization. PMTCT strategic vision 2010-2015 : Preventing mother-to-child transmission of HIV to reach the UNGASS and millennium development goals: Moving towards the elimination of paediatric HIV, December 2009. 2010. Available from: https://apps.who.int/iris/ handle/10665/44268.

6. National AIDS Committee Secretariat Ministry of Health and Medical Education. Islamic Republic of Iran AIDS progress report on monitoring of the united nations general assembly special session on HIV and AIDS. 2015.

7. Majid T, Farhad Y, Sorour A, Soheila A, Farnaz F, Hojjat Z, et al. Preventing mother-to-child transmission of HIV/AIDS: Do Iranian pregnant mothers Know about it? J Reprod Infertil. 2010;11(1):53-7. [PubMed: 23926481]. [PubMed Central: PMC3719278]. 